Supporting Information

\title{
Evolution of Hollow CuInS 2 Nanododecahedrons via Kirkendall Effect Driven by Cation Exchange for Efficient Solar Water Splitting
}

Yuemei Li, Jia Liu*, Xinyuan Li, Xiaodong Wan, Rongrong Pan, Hongpan Rong, Jiajia Liu, Wenxing Chen, Jiatao Zhang*

Beijing Key Laboratory of Construction Tailorable Advanced Functional Materials and Green Applications, School of Materials Science and Engineering, Beijing Institute of Technology, Beijing, 100081, China

E-mail: liujia86@bit.edu.cn; Zhangjt@bit.edu.cn 


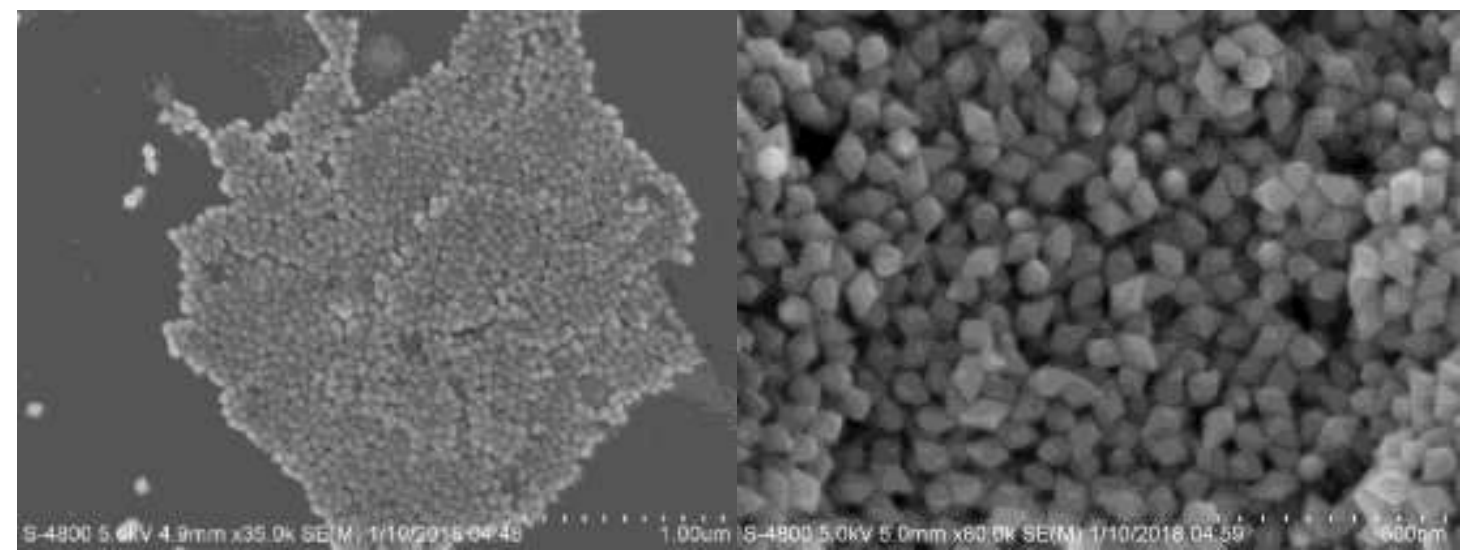

Figure S1. SEM images of the starting $\mathrm{Cu}_{7} \mathrm{~S}_{4} \mathrm{NCs}$.

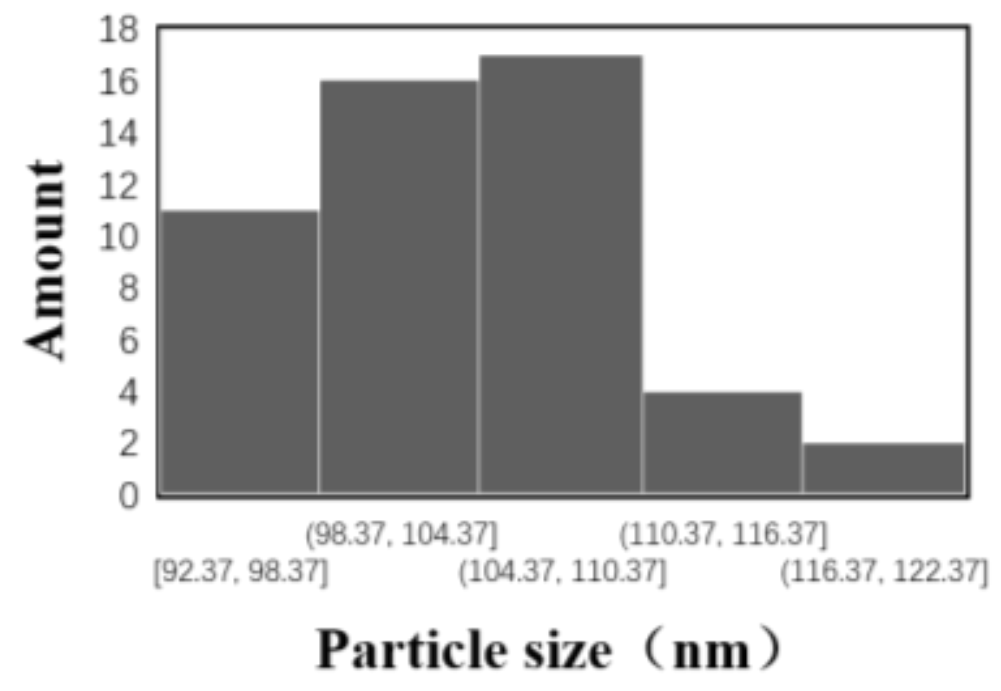

Figure S2. Partice size distribution of the $\mathrm{Cu}_{7} \mathrm{~S}_{4} \mathrm{NCs}$ (longitudinal direction). 


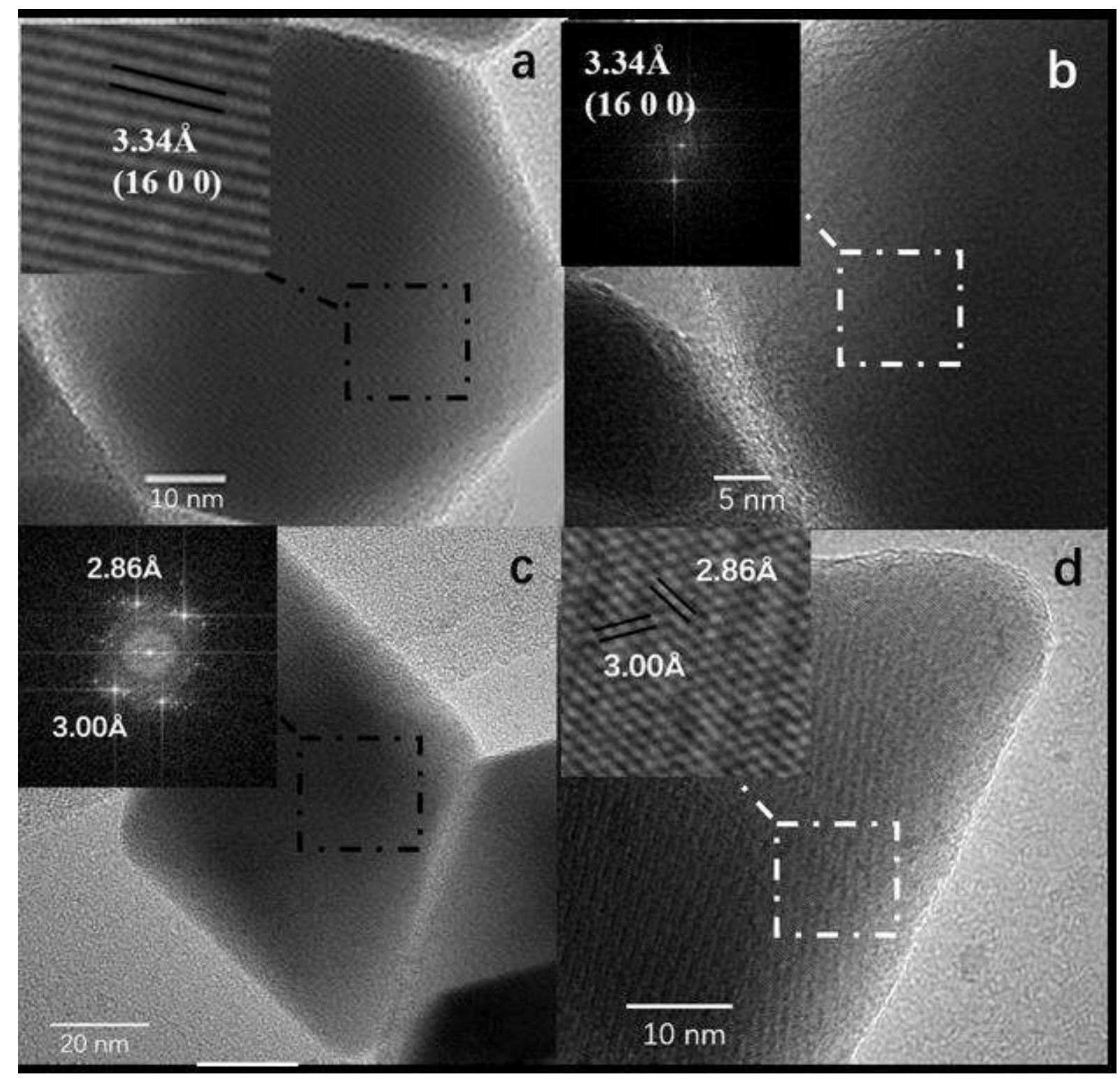

Figure S3. (a-d) HRTEM images of the $\mathrm{Cu}_{7} \mathrm{~S}_{4} \mathrm{NCs}$ and the corresponding FFT patterns taken from the square box. 


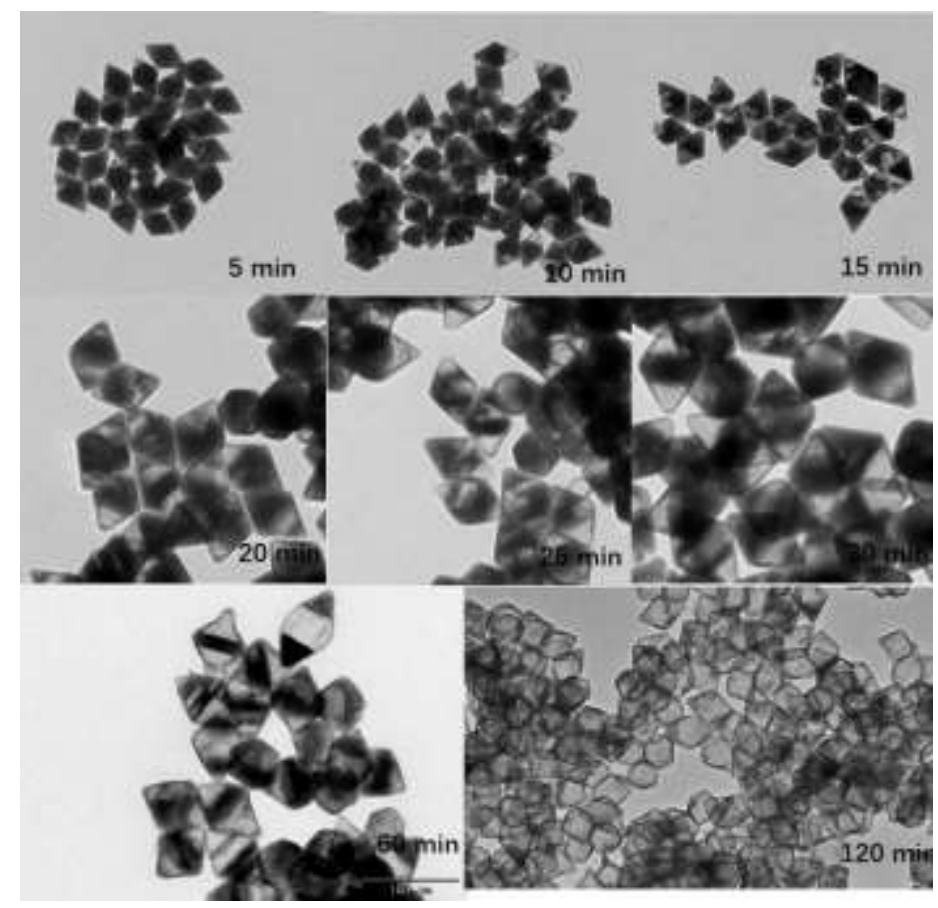

Figure S4. Additional TEM images showing the structural evolution of $\mathrm{Cu}_{7} \mathrm{~S}_{4}$ nanododecahedrons after initiating the cation exchange reaction between $\mathrm{Cu}^{+}$and $\mathrm{In}^{3+}$.

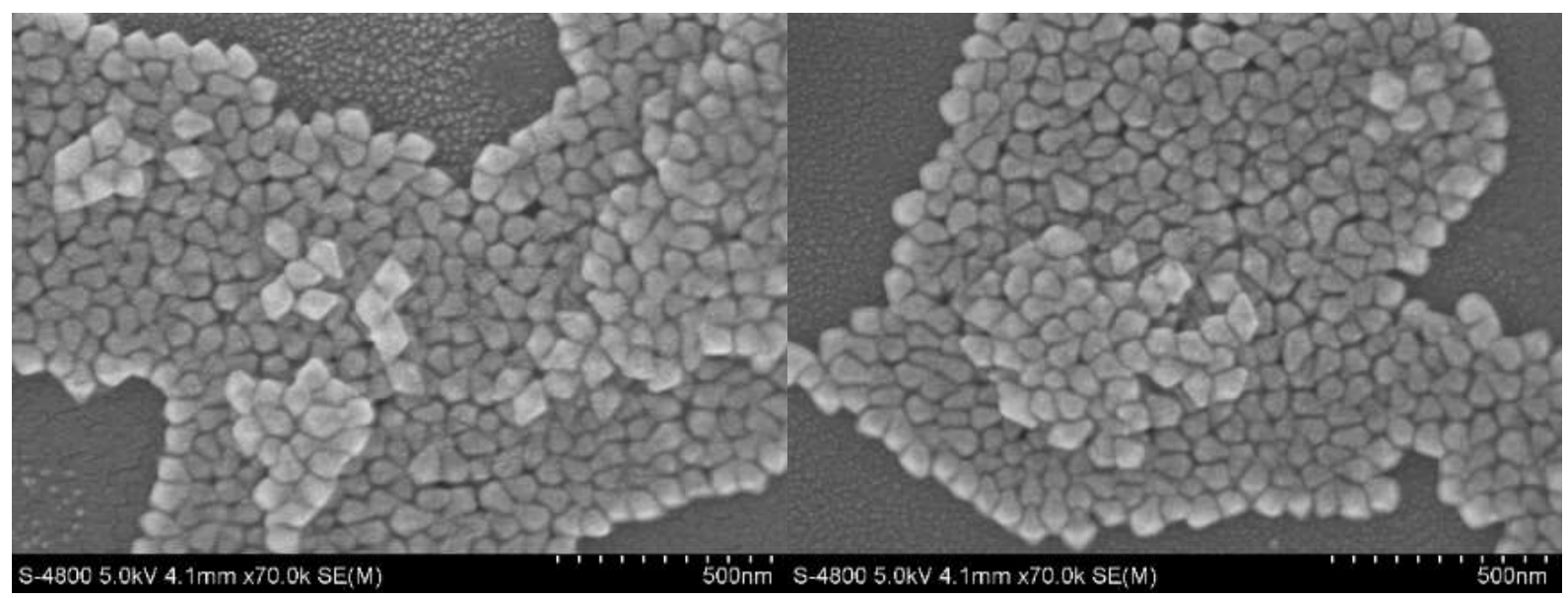

Figure S5. SEM images of the NCs obtained after initiating the cation exchange reaction between $\mathrm{Cu}^{+}$and $\mathrm{In}^{3+}$ for $120 \mathrm{~min}$. 


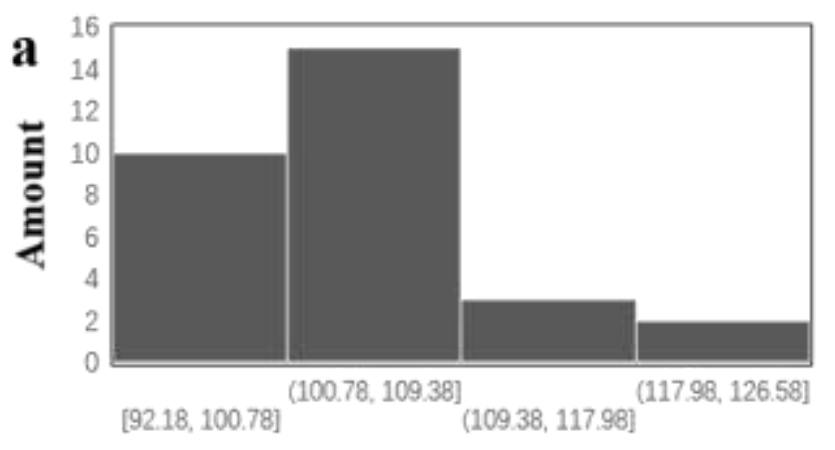

Particle size (nm)

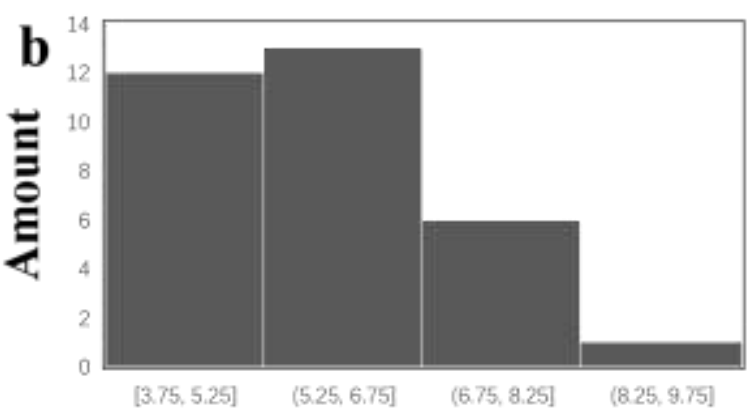

Thickness of CIS shell(nm)

Figure S6. (a) Partice size distribution of the hollow $\mathrm{CuInS}_{2} \mathrm{NCs}$ (longitudinal direction).(b) thickness distribution of $\mathrm{CuInS}_{2}$ shell

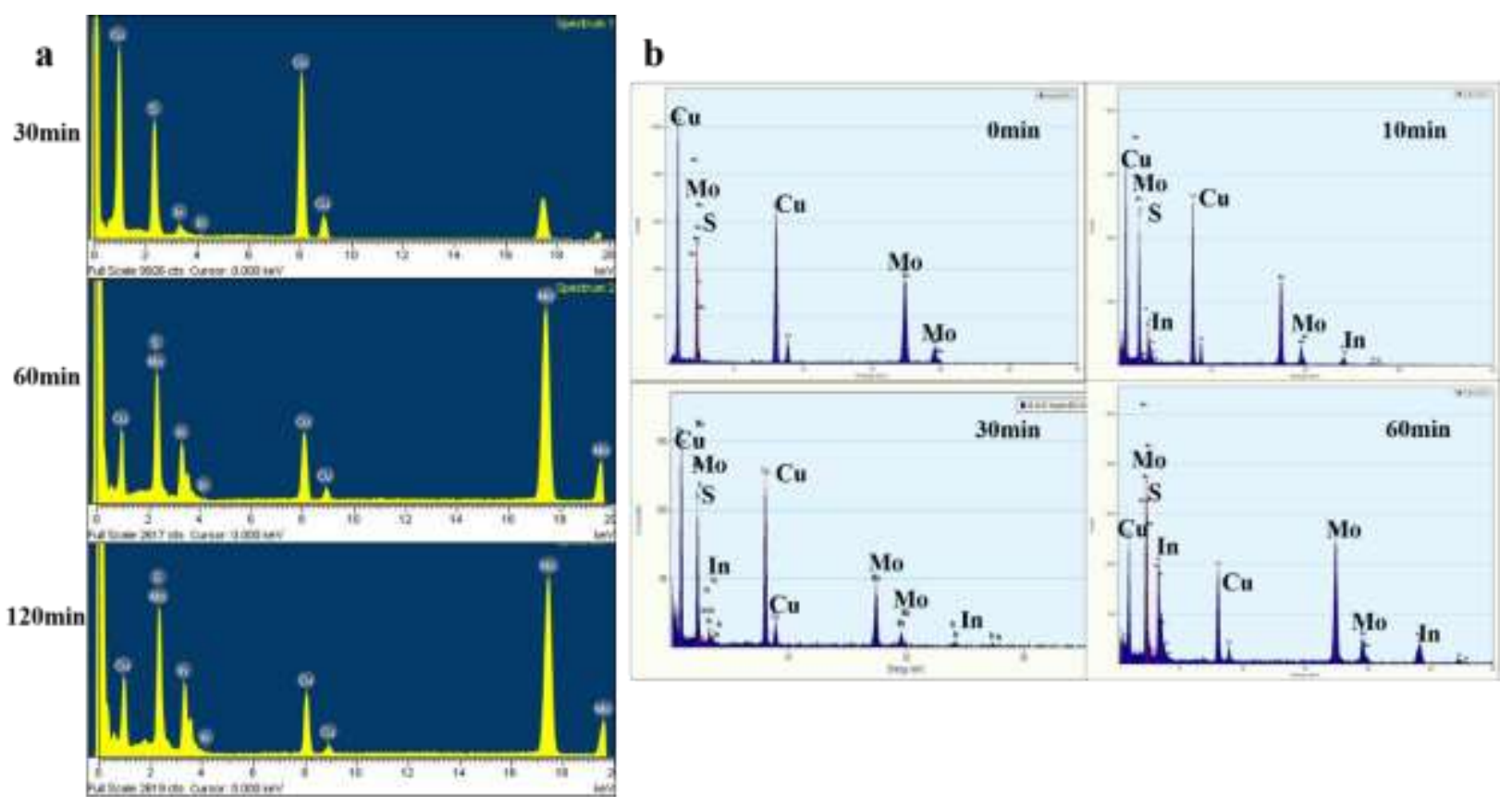

Figure S7. EDS spectra of elemental composition of the $\mathrm{Cu}_{2-\mathrm{x}} \mathrm{S}$ nanododecahedrons with the proceeding of cation exchange between $\mathrm{Cu}^{+}$and $\mathrm{In}^{3+}$.(a) using a transmission electron microscope (FEI Tecnai G2 F20 S-Twin, an acceleration voltage of 200kV) equipped with an Xray energy-dispersive spectroscopy detector. (b) using a transmission electron microscope (FEI Tecnai G2 F30 S-Twin, an acceleration voltage of 300kV) equipped with an X-ray energydispersive spectroscopy detector. 

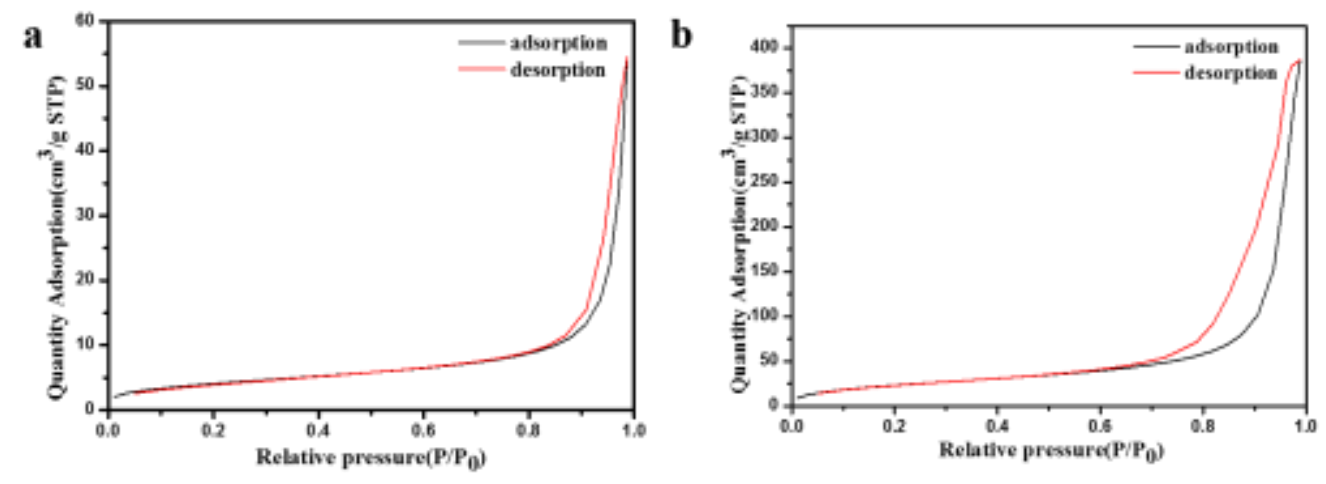

Figure S8. $\mathrm{N}_{2}$ adsorption-desorption spectra. (a) $\mathrm{N}_{2}$ adsorption-desorption spectra of $\mathrm{Cu}_{7} \mathrm{~S}_{4}$ (b) $\mathrm{N}_{2}$ adsorption-desorption spectra of the hollow $\mathrm{CuInS}_{2}$ achieved after reaction for $120 \mathrm{~min}$

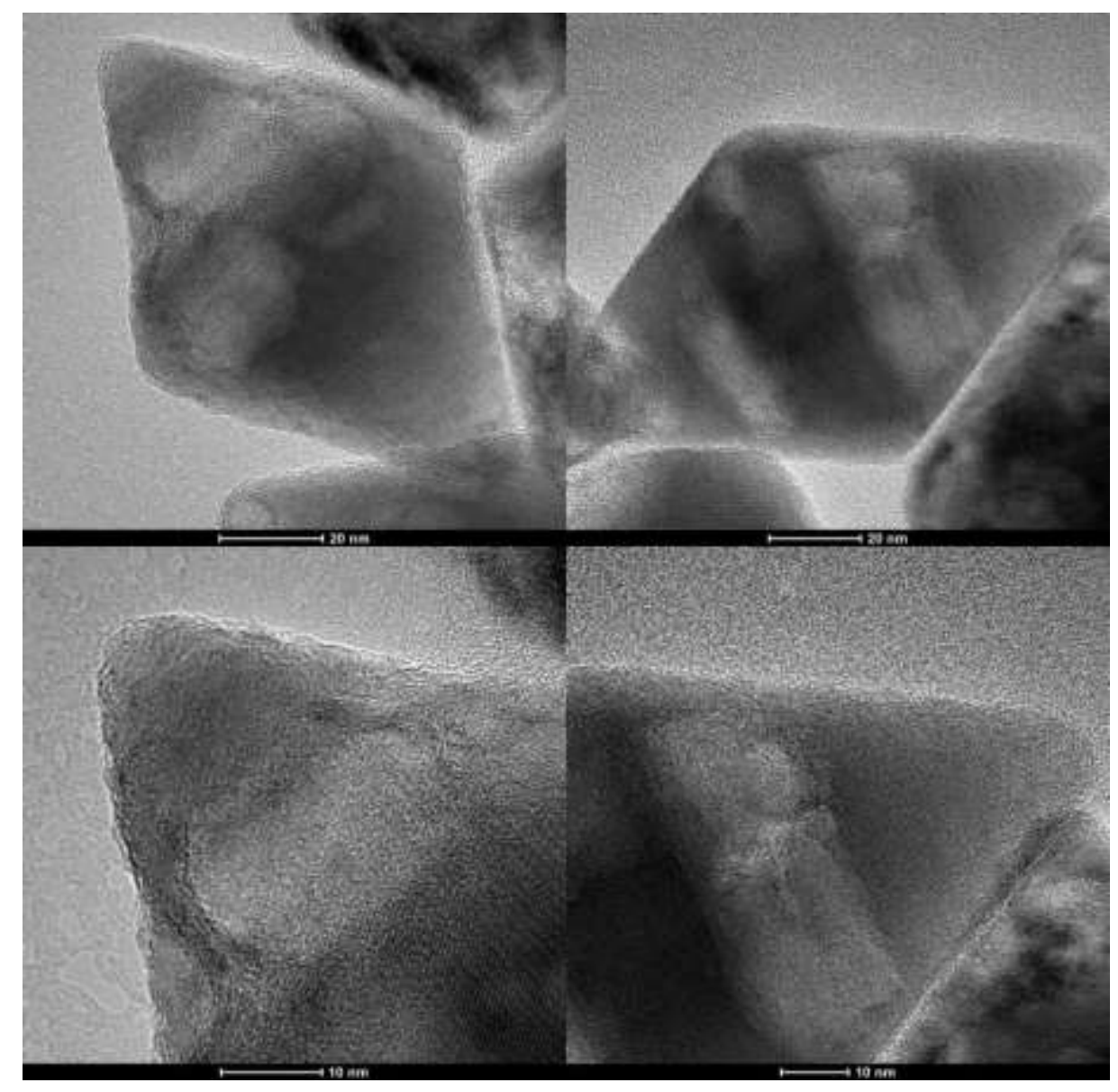

Figure S9. HRTEM images of the NCs obtained after initiating cation exchange between $\mathrm{Cu}^{+}$and $\mathrm{In}^{3+}$ for $30 \mathrm{~min}$. 


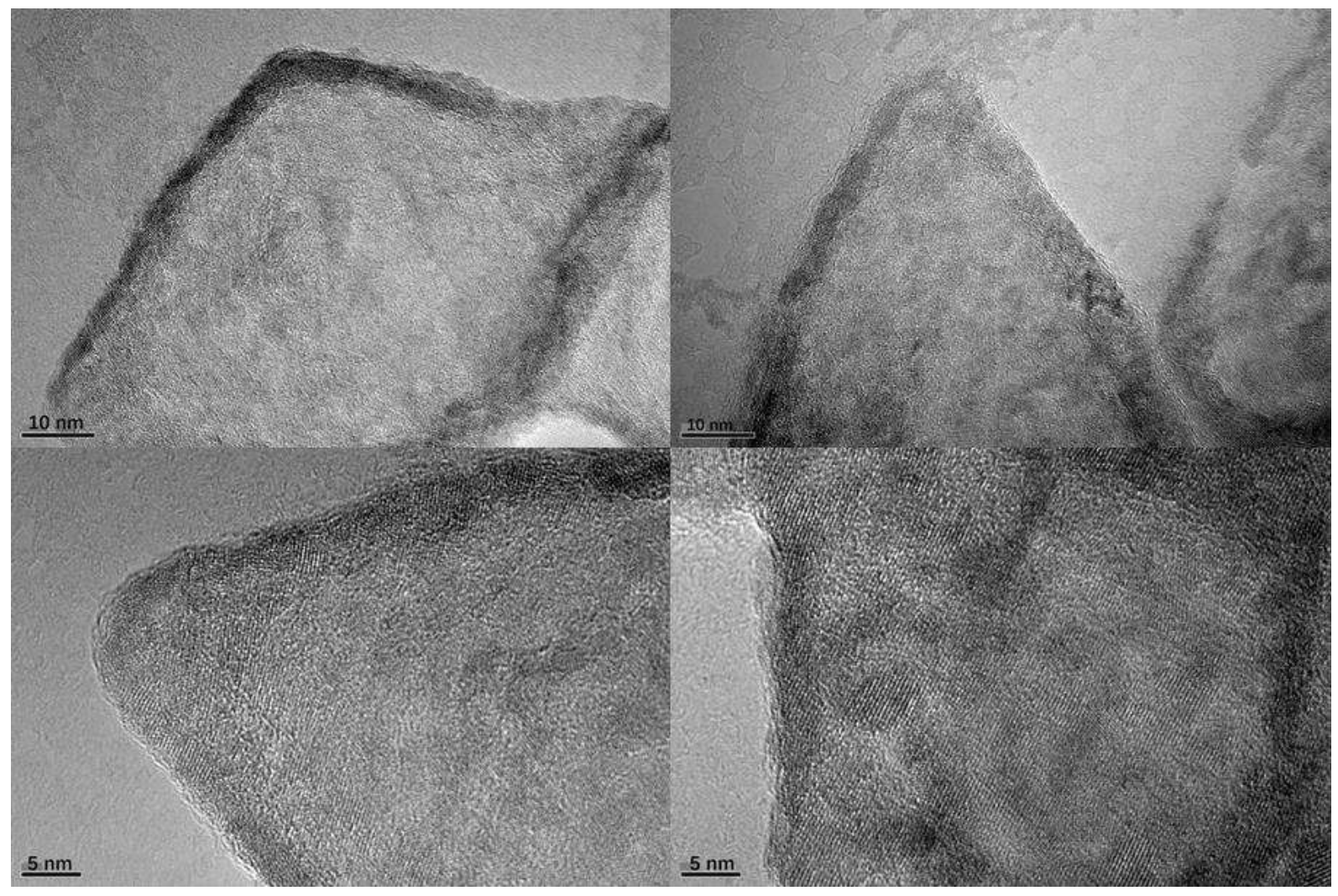

Figure S10. HRTEM images of the NCs obtained after initiating cation exchange between $\mathrm{Cu}^{+}$and $\mathrm{In}^{3+}$ for $120 \mathrm{~min}$.
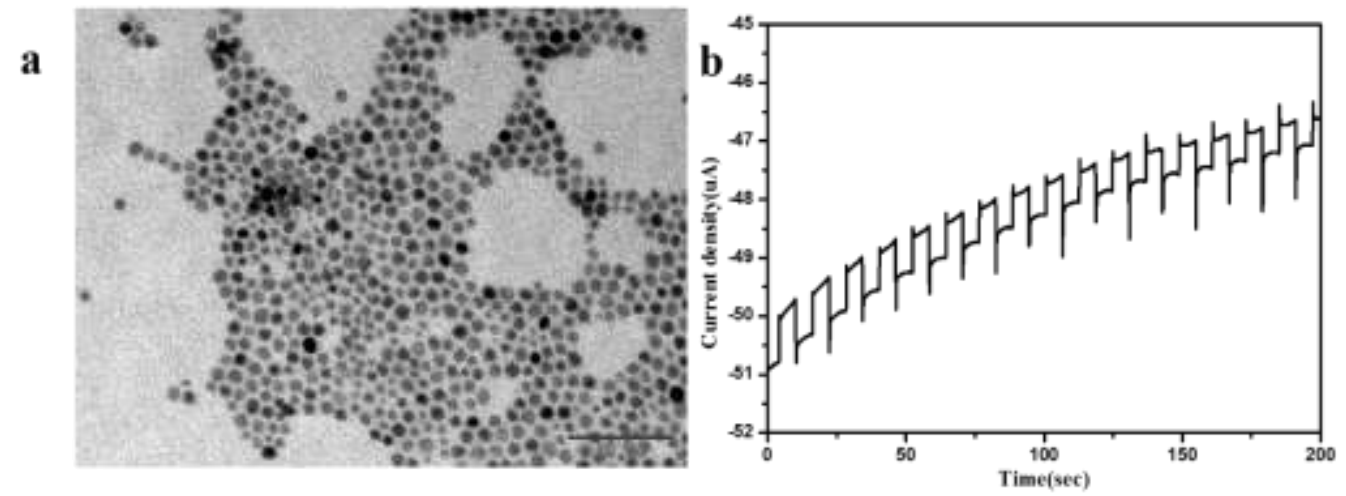

Figure S11. (a) TEM image and (b) the photocurrent density-time curve (at a bias of $0.3 \mathrm{~V}$ vs $\mathrm{RHE}$ ) for the solid $\mathrm{CuInS} \mathrm{S}_{2} \mathrm{NCs}$. 


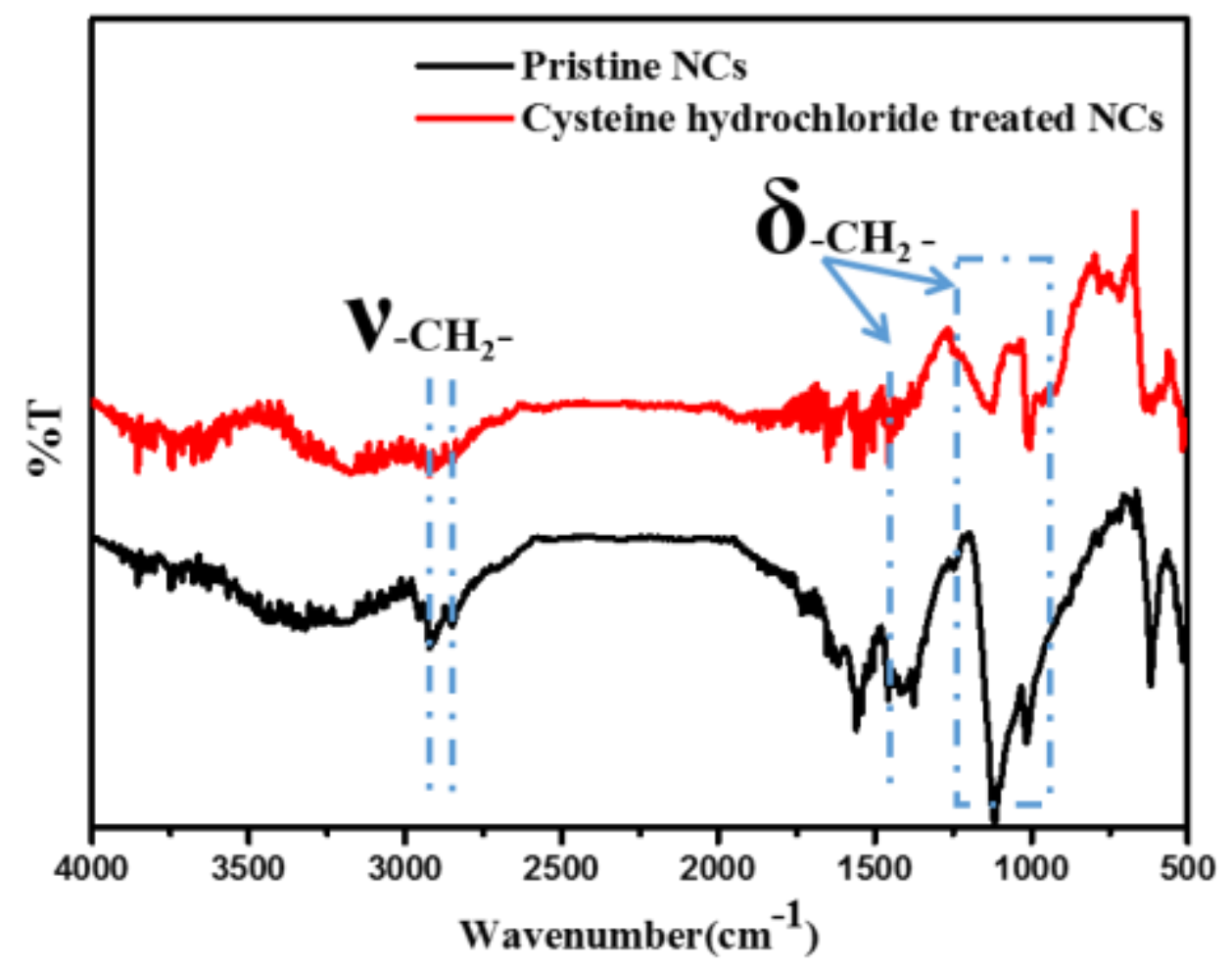

Figure S12. To facilitate the dispersion of the as-prepared NCs in water phase for performing photocatalytic $\mathrm{H}_{2}$ evolution reaction, a ligand exchange process was carried out in the aim of replacing the oleic acid capping ligands with cysteine hydrochloride. The FT-IR spectra of NCs before and after the ligand exchange reaction between oleic acid and cysteine hydrochloride suggest that the surface passivation effect caused by the insulating ligands can be alleviated after the ligand exchange process. In specific, it can be seen that after the ligand exchange process, the peaks located at $2853 \mathrm{~cm}^{-1}$ and $2926 \mathrm{~cm}^{-1}$ arising from the stretching vibration of $\mathrm{C}-\mathrm{H}$ in $-\mathrm{CH}_{2}$ groups (the major component of oleic acid molecular) were obviously decreased, accompanied with the reduction in the peaks located at $1465 \mathrm{~cm}^{-1}$ and $1350 \sim 1150 \mathrm{~cm}^{-1}$ that are ascribed to the bending vibrations of $\mathrm{C}-\mathrm{H}$ in $-\mathrm{CH}_{2}$ groups. 